\title{
Development and Validation of RP-HPLC Method for Azilsartan Medoxomil Potassium Quantitation in Human Plasma by Solid Phase Extraction Procedure
}

\author{
Paras P. Vekariya and Hitendra S. Joshi \\ Department of Chemistry, Saurashtra University, Rajkot 36005, India \\ Correspondence should be addressed to Hitendra S. Joshi; drhsjoshi49@gmail.com
}

Received 21 June 2013; Accepted 14 August 2013

Academic Editors: I. P. Gerothanassis, B. Liu, and S. Pandey

Copyright (C) 2013 P. P. Vekariya and H. S. Joshi. This is an open access article distributed under the Creative Commons Attribution License, which permits unrestricted use, distribution, and reproduction in any medium, provided the original work is properly cited.

\begin{abstract}
Simple and rapid reverse phase high-performance liquid chromatography (RP-HPLC) method was developed and validated using solid phase extraction (SPE) technique for the determination of Azilsartan Medoxomil Potassium (AMP) in human plasma; detection was carried out by photo diode array detector. Chromatographic separation of the analyte AMP was achieved within $7.5 \mathrm{~min}$ by Waters symmetry $\mathrm{C}_{18}(4.6 \times 250 \mathrm{~mm}, 5 \mu \mathrm{m})$ column, mobile phase was $25 \mathrm{mM}$ ammonium acetate buffer (pH 5.5 ): acetonitrile $55: 45 \mathrm{v} / \mathrm{v}$, flow rate was $1.0 \mathrm{~mL} / \mathrm{min}$, and the detection was carried out at $254 \mathrm{~nm}$. Calibration curve was linear $\left(r^{2}>\right.$ 0.9985 ) in the range of $1.0-9.0 \mu \mathrm{g} / \mathrm{mL}$, limit of detection (LOD) and limit of quantitation (LOQ) were $0.150 \mu \mathrm{g} / \mathrm{mL}$ and $0.400 \mu \mathrm{g} / \mathrm{mL}$, respectively, and intra- and interday deviations were between $1.53-8.41 \%$ and $1.78-4.59 \%$, respectively. The overall mean recovery of AMP was $92.35 \%$. No any endogenous constituents were found to interfere at retention time of the analyte. This new RP-HPLC method was successfully validated and may be applied to conduct bioavailability and bioequivalence studies of AMP.
\end{abstract}

\section{Introduction}

Azilsartan Medoxomil Potassium is chemically named as (5-Methyl-2-oxo-1,3-dioxol-4yl) methyl 2-ethoxy-1-\{[2' (5-oxo-4,5-dihydro-1,2,4-oxadiazol-3-yl) biphenyl-4-yl]methyl\}-1H-benzimidazole-7-carboxylate monopotassium salt (Figure 1). It is a white crystalline powder which is practically insoluble in water, freely soluble in methanol, dimethylsulfoxide, and dimethylformamide, soluble in acetic acid, slightly soluble in acetone, and acetonitrile and very slightly soluble in tetrahydrofuran and 1-octanol [1].

The US Food and Drug Administration (FDA) has approved Edarbi tablet (Azilsartan Medoxomil Potassium) on February 25, 2011, to treat hypertension in adults. It is available in $80 \mathrm{mg}$ and $40 \mathrm{mg}$ dosages, with the recommended dosage set at $80 \mathrm{mg}$ once in a day [2].

Angiotensin II hormone plays a vital role in activation of renin-angiotensin-aldosterone system as well as in regulation of blood pressure, fluid-electrolyte balance, and also in pathophysiology of hypertension. Activation of type 1 angiotensin receptor which is a member of $\mathrm{G}$ protein coupled receptor efficiently controls the numerous effects of AII which are vasoconstriction, secretion of aldosterone and vasopressin and cellular proliferation. So blocking of AII receptor will also block receptor-1, and it will lead to termination of the whole course of action mentioned above; so AII blocker will be helpful in the management of cardiovascular and renal diseases as therapeutic agent [3].

The active moiety of AMP is revealed by hydrolysis of the medoxomil ester and it converts into Azilsartan which is an active angiotensin II receptor blocker and more effective in lowering blood pressure within 24 hours as compared to valsartan and olmesartan [4-6].

The literature survey shows that there is only a single method available for quantitation of Azilsartan Medoxomil Potassium and Chlorthalidone in pharmaceutical dosage form [7]. As per our findings, there is not any method reported for quantitation of AMP in human plasma thus it is inevitable to develop such a sensitive, rapid, and accurate 
<smiles>[Z7]Oc1nc2cccc(C(=O)OCc3oc(=O)oc3C)c2n1Cc1ccc(-c2ccccc2-c2noc(=O)[nH]2)cc1</smiles>

FIgURE 1: Chemical structure of lafutidine hydrochloride salt.

method which could be used to investigate further bioavailability and bioequivalence studies.

\section{Experimental}

2.1. Materials and Reagents. Pharmacopoeial grade standard of Azilsartan Medoxomil Potassium was gifted by Ami Lifesciences Private Limited, Baroda. LC grade methanol was purchased from Spectrochem Pvt. Ltd., Baroda, the water used was purified by milli-Q water assembly, analytical grade ammonium acetate was obtained from Spectrochem Pvt. Ltd., and solid phase extraction cartridges (Strata-X) were purchased from Phenomenex.

2.2. Instrumentation. The chromatographic system used to perform development and validation of this method was comprised of an LC-10ATvp binary pump, an SPD-M10Avp photo-diode array detector, and a Rheodyne manual injector model $7725 \mathrm{i}$ with $20 \mu \mathrm{L}$ loop (Shimadzu, Kyoto, Japan), connected to a multi-instrument data acquisition and data processing system (LC Solution, Shimadzu).

2.3. Biological Samples. Human blank plasma samples for the development and validation of the method were obtained from government recognise laboratory.

2.4. Chromatographic Conditions. Chromatographic analysis was performed on a reverse phase column purchased from Waters, symmetry $\mathrm{C}_{18}(15 \mathrm{~cm}, 4.6 \times 250 \mathrm{~mm}, 5 \mu \mathrm{m})$ part number WAT054275, serial number 022638193236. The mobile phase consisted of $25 \mathrm{mM}$ ammonium acetate buffer ( $\mathrm{pH}$ 5.5): methanol 55:45, v/v. The flow rate of the mobile phase was adjusted to $1.0 \mathrm{~mL} / \mathrm{min}$, retention time of analyte was $7.5 \mathrm{~min}$, and the injection volume was $20 \mu \mathrm{L}$. Detection was performed at $254 \mathrm{~nm}$.

2.5. Preparation of Stock Solution and Spiked Plasma Samples. The stock solution of AMP was prepared in methanol at concentration of $1.0 \mathrm{mg} / \mathrm{mL}$. Working solution of $50 \mu \mathrm{g} / \mathrm{mL}$ was prepared by appropriately diluting the stock solution of AMP in methanol: water 50:50 v/v. Working solution of AMP was used to prepare the spiking stock solution for preparation of nine points of calibration curve $(1-9 \mu \mathrm{g} / \mathrm{mL})$ and quality control samples at three concentration levels (1.5,
4.5 , and $8.0 \mu \mathrm{g} / \mathrm{mL})$. All stock and working solutions were stored in refrigerator (at $2-8^{\circ} \mathrm{C}$ ) when not in use. The spiked plasma samples were prepared by adding $25 \mu \mathrm{L}$ of respective spiking stock solution in $475 \mu \mathrm{L}$ of blank plasma.

2.6. Sample Preparation and Extraction Procedure. Extraction was performed by solid phase extraction procedure which is a very efficient technique, and the samples extracted by this procedure are untainted compared to those extracted by other techniques. Sample extracted by this method shows good recovery results; so it was decided to conduct the method validation by using SPE technique to achieve more efficient data of bioavailability and equivalence studies.

$475 \mu \mathrm{L}$ of plasma was spiked with $0.25 \mu \mathrm{L}$ of respective QC and calibration standard in glass tube, mixed with $250 \mu \mathrm{L}$ of $10 \mathrm{mM}$ ammonium acetate buffer, and vortexed thoroughly then mixture was loaded into Strata-X cartridge which was preconditioned by $2 \mathrm{~mL}$ methanol followed by $2 \mathrm{~mL}$ water; cartridge was washed by $1 \mathrm{~mL}$ water two times. Then cartridge was transferred into clean test tube, the analyte was eluted in $1.0 \mathrm{~mL}$ methanol, and then $20 \mu \mathrm{L}$ volume is injected into HPLC system.

2.7. Method Validation. The validation was executed as per "Guidance for Industry: Bioanalytical Method Validation" from the United States Food and Drug Administration [8].

2.7.1. Selectivity. The selectivity of the method was performed to ensure absolute separation of AMP from the biological endogenous components of the human plasma. Selectivity was carried out by analysing seven different lots of blank human plasma by solid phase extraction procedure given above.

2.7.2. Linearity. Five standard curves of nine different concentration standards and two blank samples have been assayed, but only nine concentration standards were included in the calibration curve, whereas blank samples were used to check interference and contamination. Each calibration curve should meet the following acceptance criteria: deviation at LLOQ level must be lower than 20\% and not more than $15 \%$ deviation for the rest of the standards other than LLOQ.

2.7.3. Precision and Accuracy. Interday and intraday precision and accuracy were evaluated by five spiked samples at analyzing three different concentrations of $\operatorname{AMP}(1.5,4.5$, and $8.0 \mu \mathrm{g} / \mathrm{mL})$. Within batch, precession and accuracy were determined by repeated analysis of five spiked samples of AMP at each QC level. Intraday precession and accuracy were determined by repeated analysis of three consecutive days ( 5 series per day). The concentration of each sample was determined using standard curves prepared and analysed on the same day.

2.7.4. Matrix Effect. Matrix effect was evaluated by comparing peak areas of extracted samples using five different lots of human plasma in triplicate at three concentration level of analyte $(1.5,4.5$, and $8.0 \mu \mathrm{g} / \mathrm{mL})$; percentage RSD 


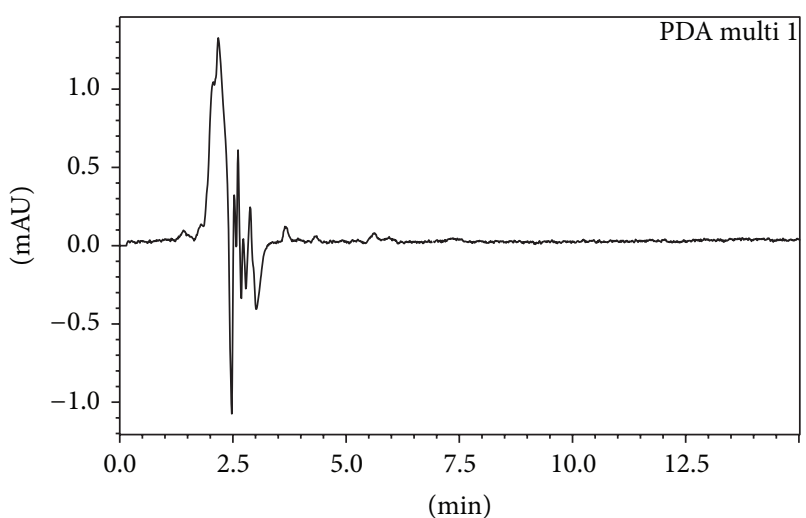

(a)

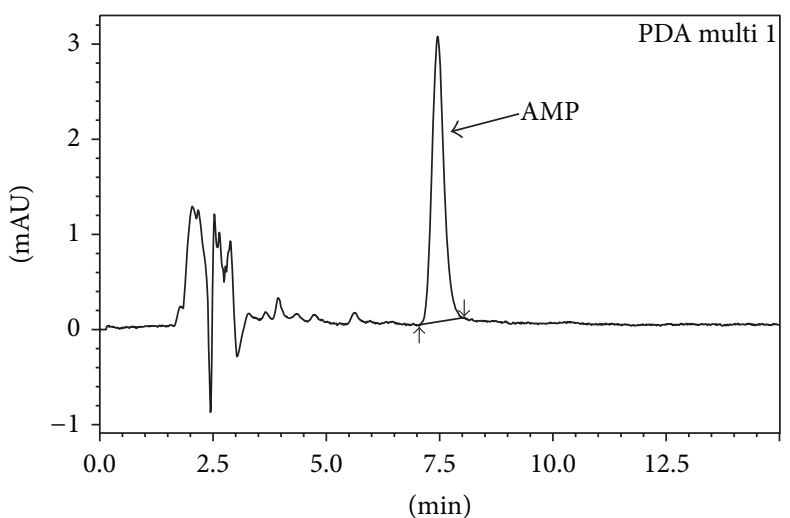

(b)

FIGURE 2: HPLC-PDA chromatograms of blank plasma sample and LLOQ (1.0 $\mu \mathrm{g} / \mathrm{mL})$ standard (a); chromatogram of extracted blank plasma (b); Chromatogram of extracted LLOQ sample spiked with $1.0 \mu \mathrm{g} / \mathrm{mL}$ of calibration standard.

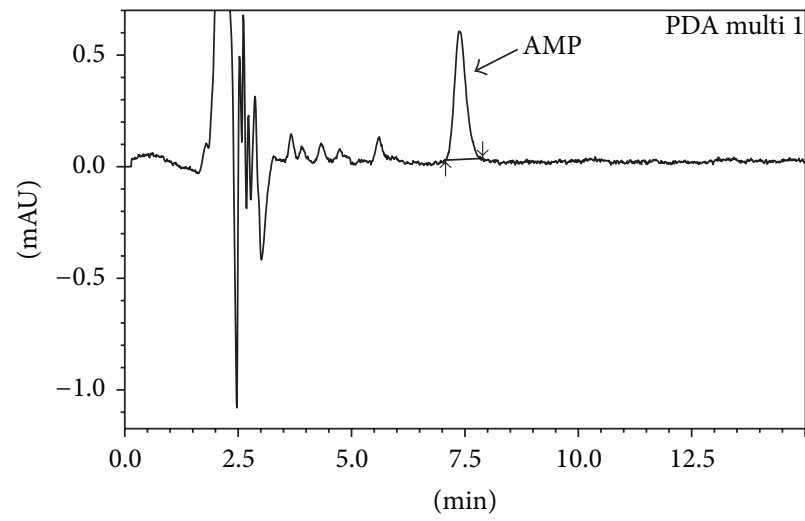

(a)

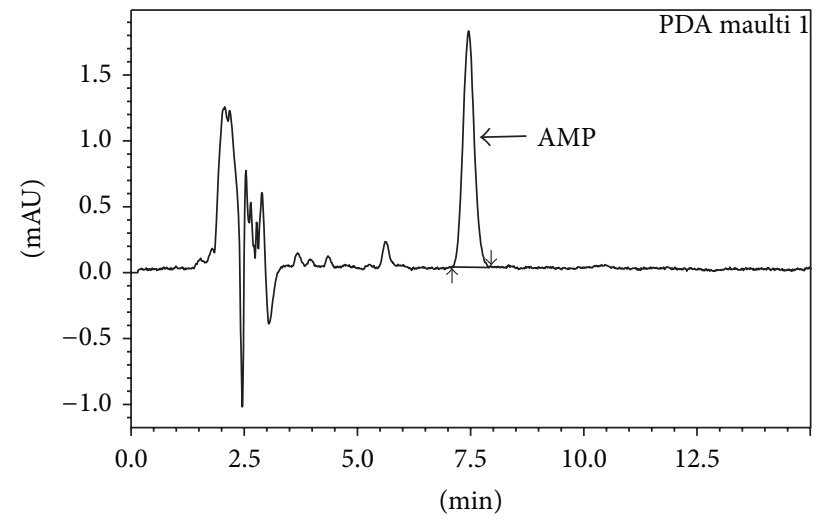

(b)

FIGURE 3: HPLC-PDA chromatogram of LOD and LOQ samples (a); Chromatogram of LOD sample (b); Chromatogram of LOQ sample.

and accuracy were calculated to check interference of matrix effect on the analyte concentration.

2.7.5. Recovery. Percentage recovery of AMP was determined by comparing the AMP peak area obtained from extracted plasma samples with aqueous sample of the same concentration standard. This procedure was followed for three different concentration levels of analyte $1.5,4.5$ and $8.0 \mu \mathrm{g} / \mathrm{mL}$.

\section{Results and Discussion}

During method development stages, we found that the results obtained by solid phase extraction method were much better than those obtained by protein precipitation extraction (especially mean recovery of analyte), so it was decided to proceed with SPE.

3.1. Sample Preparation. To accelerate drug dissociation of analyte from plasma, different buffers were tried, but with $25 \mathrm{mM}$ ammonium acetate ( $\mathrm{pH}$ 5.5), recovery and response were found better; so it was added to plasma sample, and methanol was used as eluent.

3.2. Separation. Different mobile phases were investigated by using methanol, acetonitrile, and ammonium acetate in various proportions; after several trials, mobile phase acetonitrile: $25 \mathrm{mM}$ ammonium acetate $45: 55 \mathrm{v} / \mathrm{v}$ (pH 5.5) was finalised. Flow rate selection was based on peak parameters height, asymmetry, tailing, baseline drift, and run time. Flow rate was set at $1.0 \mathrm{~mL} / \mathrm{min}$. The retention time for the investigated drug was found at $7.5 \mathrm{~min}$, and runtime was $15 \mathrm{~min}$.

Different columns have been tested, with minimal effect on the resolution of the analyte, and a Waters $\mathrm{C}_{18}$ column has been finalised because of its demonstrated smoothness and reproducibility in this method. Column-to-column reproducibility was also evaluated; only slight variations in retention time were observed when injecting the sample on column from different manufacturers and containing the same brand of packing material.

The optimum wavelength for detection of analyte was $254 \mathrm{~nm}$, at which much better detector response was 
TABLE 1: Results of 5 calibration curves for AMP determination.

\begin{tabular}{lccccccccc}
\hline Added conc. & 1 & 2 & 3 & 4 & 5 & 6 & 7 & 8 & 9 \\
\hline & 1.01 & 1.98 & 3.10 & 4.38 & 4.97 & 6.08 & 6.82 & 8.05 & 9.08 \\
& 1.04 & 1.95 & 3.08 & 4.00 & 5.00 & 5.58 & 7.22 & 7.90 & 8.85 \\
Back calculated conc. $(\mu \mathrm{g} / \mathrm{mL})$ & 1.07 & 1.93 & 3.07 & 3.87 & 4.94 & 6.11 & 7.13 & 7.81 & 8.85 \\
& 1.03 & 2.01 & 2.99 & 4.19 & 5.37 & 6.46 & 7.42 & 8.36 & 9.67 \\
& 1.08 & 2.06 & 3.08 & 3.55 & 4.70 & 6.01 & 6.76 & 7.52 & 8.92 \\
\hline Mean & 1.05 & 1.98 & 3.06 & 4.00 & 5.00 & 6.05 & 7.07 & 7.93 & 9.07 \\
Mean accuracy\% & 104.53 & 99.23 & 102.15 & 99.94 & 99.94 & 100.81 & 100.98 & 99.10 & 100.81 \\
RSD\% & 2.55 & 2.59 & 1.40 & 7.84 & 4.77 & 5.20 & 3.91 & 3.94 & 3.83 \\
\hline
\end{tabular}

TABLE 2: Parameter corresponding to linear regression obtained from 5 calibration curves of AMP.

\begin{tabular}{lccr}
\hline Calibration curve & Slope & Intercept & Correlation coefficient \\
\hline 1 & 30742.2500 & 2511.8611 & 0.9985 \\
2 & 30379.2500 & 1406.0833 & 0.9980 \\
3 & 30465.2500 & 1487.0833 & 0.9991 \\
4 & 30580.1786 & 1487.0833 & 0.9995 \\
5 & 29660.9167 & 1726.3056 & 0.9972 \\
\hline Mean & 30365.5690 & 1723.6833 & 0.9985 \\
SD & 416.7146 & 456.6344 & 0.0009 \\
SD\% & 1.3723 & 26.4918 & 0.0895 \\
\hline
\end{tabular}

obtained. For the estimation of AMP, a sharp and symmetrical peak was obtained with good baseline, which assists the accurate measurement of the peak area.

3.3. Assay Selectivity. Seven blank samples were assayed to examine selectivity of the method, and there was no interference of endogenous peak observed at the retention time of AMP (Figure 2).

3.4. Linearity. Five calibration curves were assayed as mentioned in Section 2.5, and all of them met the acceptance criteria with good regression $\left(r^{2}=0.9985\right)$. The linearity of the method was evaluated by a calibration curve in the concentration range of $1-9 \mu \mathrm{g} / \mathrm{mL}$. Calibration curve was determined by peak area versus concentration. Concentration of analyte was calculated by using mean calculation formula $Y=30365 x+1723$. Data of calibration curves is given in Tables 1 and 2 .

3.5. LOD and LOQ. Limit of detection and limit of quantification (LOD and LOQ) were estimated in accordance with the baseline to noise ratio; it should be 3 and 10 times higher than the blank plasma sample, respectively. LOD and LOQ were estimated to be $0.150 \mu \mathrm{g} / \mathrm{mL}$ and $0.400 \mu \mathrm{g} / \mathrm{mL}$, respectively; a representative chromatogram of LOD and LOQ is given in Figure 3.

3.6. Precision and Accuracy. RSD and accuracy of intraday precision were in the range $1.53-8.41 \%$ and $102-105 \%$, while for interday it was found to be 1.78-4.59 and 99-113\%, respectively. The results revealed good precision and accuracy (Table 3).

3.7. Matrix Effect. Results of matrix effect are given in Table 4. Percentage of RSD and accuracy of the injected samples for LQC was 1.19-7.54 and 99.66-104.78\%, for MQC 1.64-2.58 and 103.16-108.4\%, and for HQC was $3.43-7.11$ and $103.16-106.46 \%$, respectively. Results indicate that there is no considerable endogenous component from blank plasma interferes in the measurement of analyte.

3.8. Extraction Recovery. The extraction recovery determined for AMP was shown to be consistent, precise, and reproducible. As per result given in Table 5, mean recoveries of the three concentration levels $(1.5,4.5$, and $8.0 \mu \mathrm{g} / \mathrm{mL})$ were $93.69,91.57$, and $91.64 \%$, respectively, whereas the mean recovery between QC level is $92.35 \%$.

3.9. Stability. Table 6 summarizes stability experiments which are the bench top 24 hour at room temperature, post extraction (at $4-8^{\circ} \mathrm{C}$ after extraction), freeze thaw stability (three cycle), long-term stability for 30 days (stored at $-20^{\circ} \mathrm{C}$ ), and post preparative stability data of AMP. All the results showed the stability behaviour during these tests and no stability-related problems occurred during the validation and stability testing. The stability of working solutions was 
TABLE 3: Intra- and interday precision and accuracy of the method for determination of AMP at three levels of quality control samples.

\begin{tabular}{|c|c|c|c|c|c|c|}
\hline \multirow{2}{*}{ Added conc. $(\mu \mathrm{g} / \mathrm{mL})$} & \multicolumn{3}{|c|}{ Intraday } & \multicolumn{3}{|c|}{ Interday } \\
\hline & Detected conc. & $\mathrm{RSD} \%$ & Accuracy\% & Detected conc. $^{a}$ & $\mathrm{RSD} \%$ & Accuracy\% \\
\hline 1.5 & $1.53( \pm 0.02)$ & 1.81 & 102.02 & $1.49( \pm 0.02)$ & 1.78 & 99.98 \\
\hline 4.5 & $4.61( \pm 0.17)$ & 3.80 & 102.39 & $5.08( \pm 0.23)$ & 4.59 & 113.03 \\
\hline 8.0 & $8.41( \pm 0.33)$ & 3.94 & 105.09 & $8.11( \pm 0.31)$ & 3.94 & 101.27 \\
\hline
\end{tabular}

${ }^{\mathrm{a}} \operatorname{Mean}( \pm \mathrm{SD}, \mu \mathrm{g} / \mathrm{mL})$; intraday $n=5$ and interday $n=5$ series per day.

TABLE 4: Results of matrix effect analysing 5 different lots of blank human plasma at three different levels of quality control samples.

\begin{tabular}{|c|c|c|c|c|c|c|c|c|c|}
\hline \multirow{2}{*}{ LOT } & \multicolumn{3}{|c|}{$1.5 \mu \mathrm{g} / \mathrm{mL}$} & \multicolumn{3}{|c|}{$4.5 \mu \mathrm{g} / \mathrm{mL}$} & \multicolumn{3}{|c|}{$8.0 \mu \mathrm{g} / \mathrm{mL}$} \\
\hline & Mean $^{\mathrm{a}}$ & RSD\% & Accuracy\% & Mean $^{\mathrm{a}}$ & RSD\% & Accuracy\% & Mean $^{\mathrm{a}}$ & $\mathrm{RSD} \%$ & Accuracy\% \\
\hline A-1 & $1.54( \pm 0.07)$ & 4.48 & 102.9 & $4.64( \pm 0.08)$ & 1.92 & 103.1 & $8.29( \pm 0.28)$ & 3.43 & 103.6 \\
\hline A-2 & $1.56( \pm 0.04)$ & 2.63 & 104.5 & $4.86( \pm 0.07)$ & 1.64 & 108.0 & $8.35( \pm 0.45)$ & 5.46 & 104.4 \\
\hline A-3 & $1.49( \pm 0.02)$ & 1.19 & 99.6 & $4.72( \pm 0.10)$ & 2.23 & 105.0 & $8.37( \pm 0.59)$ & 7.11 & 103.1 \\
\hline A- 4 & $1.52( \pm 0.05)$ & 3.20 & 101.6 & $4.75( \pm 0.08)$ & 1.80 & 105.7 & $8.51( \pm 0.45)$ & 5.36 & 106.4 \\
\hline A-5 & $1.57( \pm 0.12)$ & 7.54 & 104.7 & $4.72( \pm 0.12)$ & 2.58 & 105.0 & $8.49( \pm 0.30)$ & 3.63 & 106.1 \\
\hline
\end{tabular}

${ }^{\mathrm{a}}( \pm \mathrm{SD}, \mu \mathrm{g} / \mathrm{mL})$.

TABLE 5: Absolute recovery of AMP from $0.5 \mathrm{~mL}$ of plasma at three different levels of quality control samples.

\begin{tabular}{lccc}
\hline & $1.5 \mu \mathrm{g} / \mathrm{mL}$ & $4.5 \mu \mathrm{g} / \mathrm{mL}$ & $8.0 \mu \mathrm{g} / \mathrm{mL}$ \\
\hline \% Mean recovery within QC level & 93.69 & 91.57 & 91.64 \\
\% Mean recovery between QC & & \\
level & 92.35 & \\
SD & & 1.31 \\
\% CV & 1.35 \\
\hline
\end{tabular}

TABLE 6: Stability data of AMP at three levels of quality control standard samples.

\begin{tabular}{lccc}
\hline & $\begin{array}{c}1.5 \mu \mathrm{g} / \mathrm{mL} \\
\text { Accuracy }\end{array}$ & $\begin{array}{c}4.5 \mu \mathrm{g} / \mathrm{mL} \\
\text { Accuracy }^{\mathrm{a}}\end{array}$ & $\begin{array}{c}8.0 \mu \mathrm{g} / \mathrm{mL} \\
\text { Accuracy }^{\mathrm{a}}\end{array}$ \\
\hline Bench top & $98.51( \pm 1.83)$ & $104.71( \pm 3.47)$ & $101.2( \pm 1.45)$ \\
Process & $98.12( \pm 2.78)$ & $103.37( \pm 4.24)$ & $101.49( \pm 0.67)$ \\
Freeze and thaw & $102.47( \pm 4.33)$ & $101.94( \pm 2.62)$ & $98.94( \pm 1.68)$ \\
Long term & $99.75( \pm 2.59)$ & $104.34( \pm 4.19)$ & $101.75( \pm 1.65)$ \\
\hline
\end{tabular}

${ }^{\mathrm{a}}$ Mean $( \pm \mathrm{SD})$.

tested, and on the basis of the results obtained these solutions were at least stable for $6 \mathrm{~h}$.

\section{Conclusion}

We have developed a suitable method for the determination of Azilsartan Medoxomil Potassium in human plasma by solid phase extraction procedure. To our knowledge, this is the first description on development and validation of AMP by using RP-HPLC method which gives a good resolution in short analysis time $(<7.5 \mathrm{~min})$. The method is simple, sensitive, specific, and reproducible and may be used in bioavailability and bioequivalence studies.

\section{Acknowledgments}

The authors are thankful to Ami Lifesciences Pvt. Ltd. for supplying them with the Azilsartan Medoxomil Potassium; facilities and grants were given under the UGC-Special Assistance Program Department of Research Support (SAPDRS), Department of Science and Technology (DST) New Delhi, Fund for Improvement of Science and Technology (FIST), National Facility for Drug Discovery and Department of Chemistry, Saurashtra University, Rajkot. 360 005, India. The authors are thankful to them for providing analytical facilities.

\section{References}

[1] European Medicines Agency, "Edarbi (Azilsartan Medoxomil Potassium)," Assessment Report Procedure no. EMEA/H/C/ 002293, 2011.

[2] Press announcement by The U.S. Food and Drug Administration, http://www.fda.gov/Newsroom/PressAnnouncements/ ucm244722.htm.

[3] M. Gasparo, K. J. Catt, T. Inagami, J. W. Wright, and T. Unger, "International union of pharmacology. XXIII. The angiotensin II receptors," Pharmacological Reviews, vol. 52, no. 3, pp. 415$472,2000$.

[4] M. Ojima, H. Igata, M. Tanaka et al., "In vitro antagonistic properties of a new angiotensin type 1 receptor blocker, azilsartan, in receptor binding and function studies," Journal of Pharmacology and Experimental Therapeutics, vol. 336, no. 3, pp. 801-808, 2011.

[5] G. L. Bakris, D. Sica, M. Weber et al., "The comparative effects of azilsartan medoxomil and olmesartan on ambulatory and clinic blood pressure," Journal of Clinical Hypertension, vol. 13, no. 2, pp. 81-88, 2011.

[6] W. B. White, M. A. Weber, D. Sica et al., "Effects of the angiotensin receptor blocker azilsartan medoxomil versus olmesartan and valsartan on ambulatory and clinic blood pressure in patients with stages 1 and 2 hypertension," Hypertension, vol. 57, no. 3, pp. 413-420, 2011. 
[7] K. Madhubabu and K. Bikshalbabu, "Reverse phase-Hplc method development and validation of azilsartan medoxomil and chlortalidone in pharmaceutical dosage form," Journal of Atoms and Molecules, vol. 2, no. 1, pp. 117-126, 2012.

[8] "Guidance for industry: bio analytical method validation," US Department of Health and Human Services, Food and Drug Administration, CDER, Rockville, Md, USA, May 2001, http://www.fda.gov/downloads/Drugs/GuidanceComplianceRegulatoryInformation/Guidances/ucm070107.pdf. 

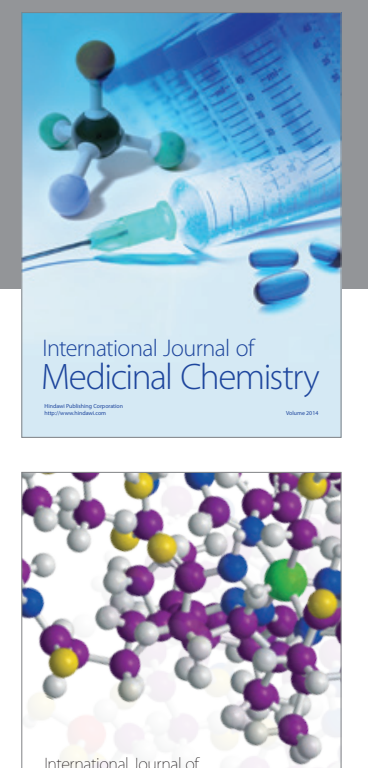

\section{Carbohydrate} Chemistry

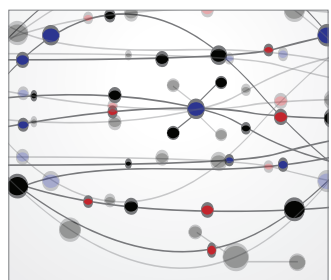

The Scientific World Journal
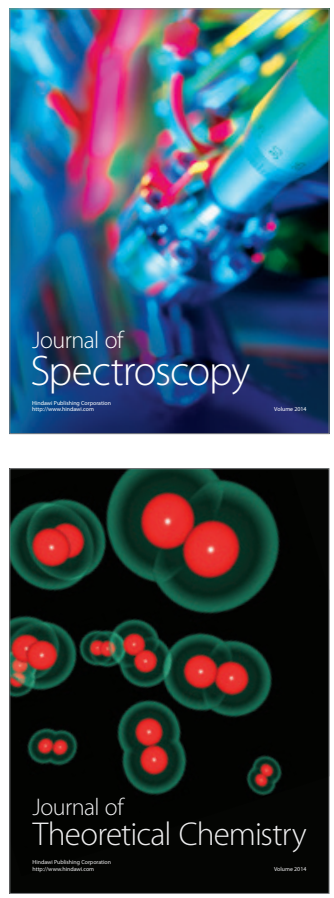
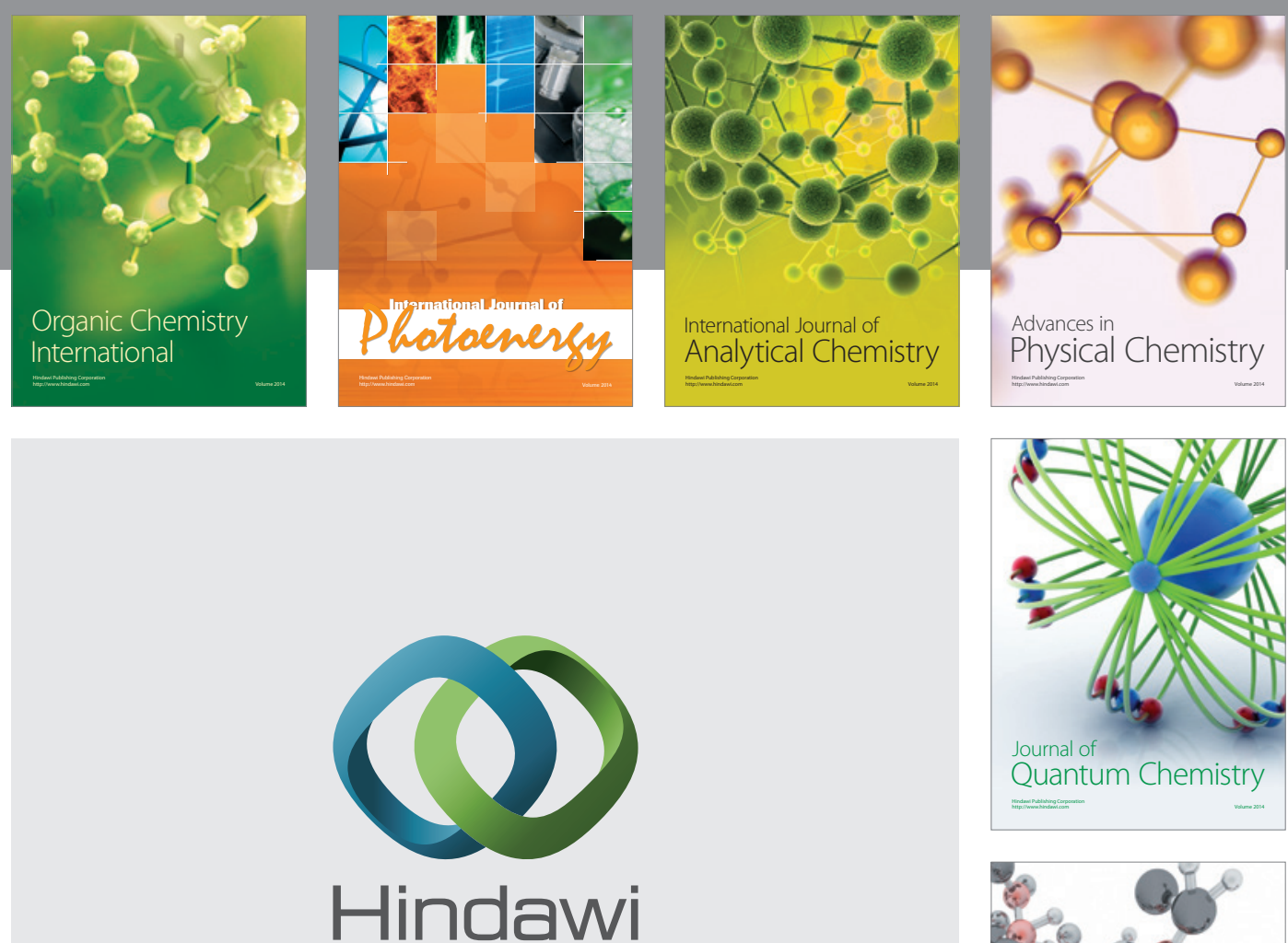

Submit your manuscripts at

http://www.hindawi.com

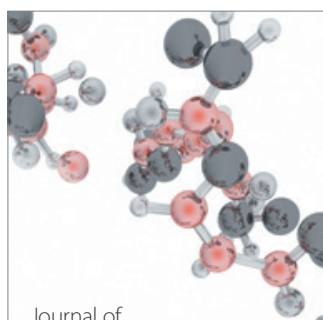

Analytical Methods

in Chemistry

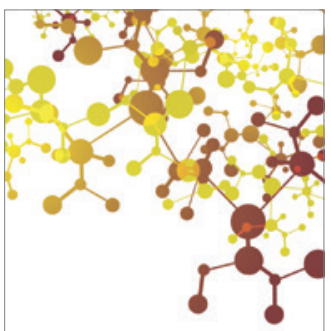

Journal of

Applied Chemistry

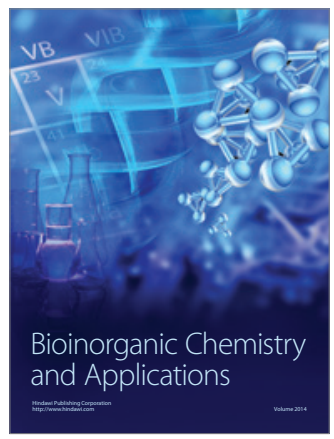

Inorganic Chemistry
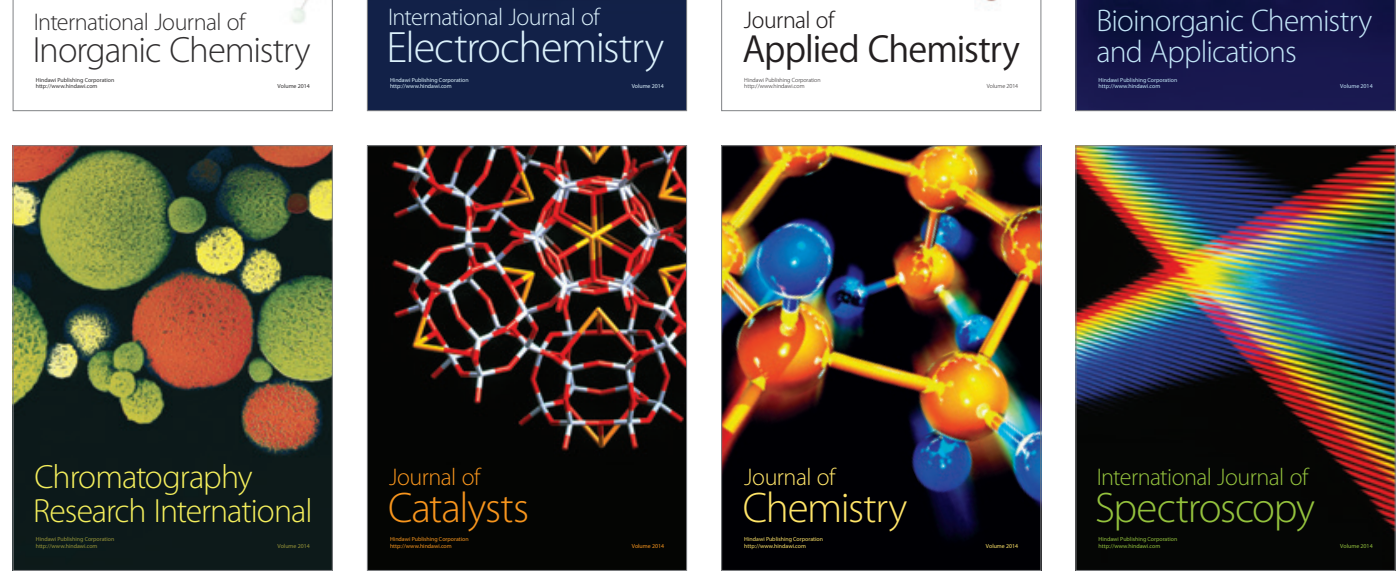